\title{
DESAFIOS E PERSPECTIVAS PARA A CARREIRA DOCENTE EM UM CENÁRIO DE EXPANSÃO DA EDUCAÇÃO SUPERIOR A DISTÂNCIA NAS INSTITUIÇÕES PRIVADAS ${ }^{1}$
}

\author{
Celia Maria Haas \\ celiahaas1@gmail.com \\ https://orcid.org/0000-0002-8462-8350 \\ Universidade Virtual do Estado de São Paulo (UNIVESP) ${ }^{2}$ \\ São Paulo, Brasil \\ Gladys Roberta Garcia \\ gladys.garcia02@gmail.com \\ https://orcid.org/0000-0001-9472-092X \\ Professora da Universidade Anhembi-Morumbi (UAM) \\ São Paulo, Brasil ${ }^{3}$
}

Recibido: 09/11/2020 Aceptado: 02/02/2021

\begin{abstract}
Resumo
Segundo o último censo feito pela Associação Brasileira de Educação a Distância (ABED) em 2018/2019 foram contabilizados 9 milhões de alunos em cursos livres, de graduação e pósgraduação oferecidos nesta modalidade, indicando um crescimento exponencial da EaD. Pelo Censo Inep/2019, há 2.450.264 matriculados nos cursos de graduação em EaD. Diante dessa expansão, como fica a carreira docente? Este estudo buscou investigar a visão e perspectiva de carreira do professor da educação superior presencial de uma instituição privada na cidade de São Paulo, considerando o impacto da expansão da EaD em sua vida profissional, além de mapear os novos papéis que surgiram na área, confirmar as tensões provocadas pela expansão da $\mathrm{EaD}$ e verificar o que os professores têm feito para se prepararem para esta nova realidade. A coleta de dados feita pela aplicação de questionários, com perguntas objetivas e dissertativas, utilizou formulários do Google Forms, enviados a professores atuantes nos cursos presenciais. Observou-se que os professores apostam na formação continuada para manter sua empregabilidade, mesmo com as ameaças e tensões, tais como diminuição de espaços de atuação, perdas salariais, uso intensivo da tecnologia, entre outras mencionadas pelos docentes. Palavras-chave: Carreira Docente. Educação a distância. Educação superior privada.
\end{abstract}

Políticas públicas em educação.

\footnotetext{
${ }^{1}$ Trabalho desenvolvido com apoio financeiro da CAPES.

${ }^{2}$ Pedagoga e Mestre em Educação: História e Filosofia da Educação pela Pontifícia Universidade Católica de São Paulo (1989); Doutora em Educação (Supervisão e Currículo) pela Pontifícia Universidade Católica de São Paulo (1996). É professora Titular da Universidade Virtual do Estado de São Paulo (UNIVESP).

${ }^{3}$ Especializada em Gestão de Pessoas e Educação Corporativa, Mestre em Educação pela Universidade Cidade de São Paulo (2020). É docente na Universidade Anhembi Morumbi- SP e produz material acadêmico/pedagógico como conteudista para a educação a distância há 10 anos.
} 


\title{
CHALLENGES AND PERSPECTIVES FOR THE TEACHING CAREER IN A SCENARIO OF EXPANSION OF HIGHER DISTANCE EDUCATION IN PRIVATE INSTITUTIONS
}

\begin{abstract}
According to the last census made by the Brazilian Association for Distance Education (ABED) in 2018/2019, 9 million students were enrolled in free, undergraduate, and graduate courses offered in this modality, indicating an exponential growth in distance education. According to the Inep / 2019 Census, there are 2,450,264 enrolled in undergraduate courses in distance education. Considering this expansion, what is the future of the teaching career? This study sought to investigate the vision and career perspective of the face-to-face higher education professors of a private institution in the city of São Paulo, taking into consideration the impact of the expansion of distance education in their professional lives, in addition to mapping the new roles that emerged in the area, the tensions caused by the expansion of distance education and verify what teachers have done to prepare for this new reality. The data collection made through the application of questionnaires, with objective and dissertation questions, used forms from Google Forms, sent to professors working in the face-to-face courses. It was observed that teachers keep on investing in their ongoing education to maintain their employability, even with threats and tensions, such as reduction of working spaces, wage losses, intensive use of technology, among others.
\end{abstract}

Keywords: Teaching Career. Distance education. Private higher education. Public policies in education.

\section{RETOS Y PERSPECTIVAS PARA LA CARRERA DOCENTE EN UN ESCENARIO DE EXPANSIÓN DE LA EDUCACIÓN SUPERIOR A DISTANCIA EN INSTITUCIONES PRIVADAS}

\begin{abstract}
Resumen
Según el último censo realizado por la Asociación Brasileña de Educación a Distancia (ABED) en 2018/2019, 9 millones de estudiantes se matricularon en cursos gratuitos, de pregrado y posgrado ofrecidos en esta modalidad, lo que indica un crecimiento exponencial en la educación a distancia. Según el Censo Inep / 2019, hay 2.450.264 matriculados en cursos de pregrado en educación a distancia. Ante esta expansión, ¿cómo es la carrera docente? Este estudio buscó indagar en la visión y perspectiva de carrera del docente de educación superior presencial de una institución privada en la ciudad de São Paulo, considerando el impacto de la expansión de la educación a distancia en su vida profesional, además de mapear los nuevos roles que surgieron en el área, las tensiones provocadas por la expansión de la educación a distancia y comprobar qué han hecho los docentes para prepararse para esta nueva realidad. La recolección de datos se realizó mediante la aplicación de cuestionarios, con preguntas objetivas y de disertación, se utilizaron formularios de Google Forms, enviados a los docentes que laboran en los cursos presenciales. Se observó que los docentes apuestan por la educación continua para mantener su
\end{abstract}


empleabilidad, aún con amenazas y tensiones, como reducción de espacios de trabajo, pérdidas salariales, uso intensivo de tecnología, entre otros mencionados por los docentes.

Palabras clave: Carrera Docente. Educación a distancia. Educación superior privada. Políticas públicas en educación.

\section{Introdução}

A globalização e o advento da tecnologia vêm provocando inúmeras transformações no mundo; entre estas pode-se admitir que até a forma como o conhecimento é adquirido tem sido alterado. Vivendo na chamada Sociedade do Conhecimento, resultante das interações nas redes sociais e colaborativas tem exigido das pessoas uma maior interação que impõe reflexões acerca de questões mais complexas, tais como as novas formas de ensino, as novas relações sociais e de trabalho, produzindo novos conhecimentos e novas práticas, levando a um processo de ensinar e aprender contínuo.

É nesse cenário de mudanças significativas na cultura e valores da sociedade, no mercado de trabalho, nas relações e no perfil profissional, que a Educação a Distância $(\mathrm{EaD})$ vem ganhando cada vez mais força e espaço em território nacional.

Os números dos censos feitos pelo Instituto Nacional de Estudos e Pesquisas Educacionais Anísio Teixeira (INEP) e pela Associação Brasileira de Educação a Distância (ABED) têm mostrado o constante alastramento da modalidade a distância, com crescimento anual de 3,8\%. A oferta de cursos também tem aumentado, nas modalidades semipresenciais e totalmente a distância, especialmente devido à flexibilização desta modalidade, tanto em horários, quanto em proposta de formação, além de uma constante expansão da oferta provocando um expressivo crescimento do número de alunos.

A ampliação da EaD sinaliza tempos de mudança para a educação superior pública e privada, pois, essa modalidade impacta fortemente a carreira docente, exigindo dos professores novas competências e afetando a perspectiva de carreira futura. Com o aumento dos cursos a distância os professores passam a sentir que seus espaços de atuação estão sendo revistos e até mesmo ameaçados. Esse crescimento tem gerado tensões como a redução de jornada e salários e ansiedade para dominar a tecnologia, exigindo dos docentes uma continua busca por qualificações e causando, muitas vezes, situações de temor pela manutenção dos empregos, levando-os a se submeteram condições precárias de trabalho. 
Nesse sentido, esse estudo visa compreender com mais profundidade os possíveis impactos da expansão da $\mathrm{EaD}$ na carreira doente, na visão do professor da educação superior presencial e busca também identificar perspectivas sobre sua própria carreira. Complementa a investigação o propósito de cotejar as tensões provocadas pela expansão da EaD, desvelando o que os professores têm feito para se prepararem para este cenário.

A coleta de dados foi feita por meio de questionários, a partir da autorização da instituição, com 35 perguntas objetivas e dissertativas, utilizando os formulários do Google Forms. Os sujeitos de pesquisa são os professores dos cursos presenciais de uma instituição privada de educação superior na cidade de São Paulo. Os questionários foram enviados para um conjunto de 450 professores e, destes 65 responderam. As informações coletadas foram tabuladas, mensuradas e analisadas, com base num cruzamento de informações, sendo organizadas em grupos de professores com opiniões semelhantes, de acordo com características como gênero, faixa etária e tempo de experiência na docência em disciplinas presenciais e a distância. Para a análise das respostas das perguntas abertas, os professores receberam números de 1 a 65 .

A Universidade privada que acolheu a pesquisa está localizada na zona leste da cidade de São Paulo criada em 1972, como uma faculdade isolada num bairro da zona leste. Cresceu bastante e se tornou universidade em 1992. Hoje, com mais de 40 anos no mercado, possui dois campi e conta com mais de 60 cursos de Graduação e Graduação Tecnológica presenciais, semipresenciais e a distância), 7 cursos Técnicos EaD, Pós-Graduação Lato Sensu e Stricto Sensu (52 cursos de Especialização, 4 Mestrados e 4 Doutorados, com programas com altas notas no MEC), presenciais, nas áreas de Saúde, Negócios, Comunicação, Ciências Jurídicas, Exatas e Turismo, entre outras e 50 cursos a distância. Além disso, possui cursos de extensão e programas com parcerias no Brasil e exterior. Possui mais de 25 mil alunos e 1300 funcionários e aproximadamente 450 professores na modalidade presencial. Atualmente faz parte de um grupo educacional de grande porte.

\section{Crescimento e tensão na educação superior a distância privada brasileira}

Segundo o último censo feito pela Associação Brasileira de Educação a Distância (ABED) em 2018/2019, há 9.374.647milhões de alunos, contabilizando também cursos livres e corporativos. 
O Censo realizado pelo Instituto Nacional de Estudo e Pesquisas Educacionais (INEP) em 2019 traz um aumento de 1,8\% em relação a 2018, no número total de matrículas na educação superior. "Em relação a 2017, a variação foi de 1,9\%. Entre 2009 e 2019, a matrícula na educação superior aumentou 43,7\%. A média de crescimento anual é de 3,6\%”. (INEP, 2019, p.15).

Outro dado significativo foi a diminuição em 3,8\% no número de matrículas nos cursos de graduação presencias entre os anos de 2018 e 2019, registrando o aumento de 19,1\% nas matrículas na modalidade a distância. Destaca ainda que no período de 2009 a 2019 houve um aumento de $192,4 \%$ nas matrículas no $\mathrm{EaD}$, enquanto o crescimento das matrículas na modalidade presencial foi de $20,3 \%$ apenas.

Estes resultados podem ser atribuídos às mudanças da legislação e do grande interesse mercantil que a modalidade a distância tem para a iniciativa privada que contabiliza $93,50 \%$ das matrículas.

A modalidade a distância, acredita-se, possui vantagens para estudantes e IES, como a flexibilidade de acesso, de horário e menor custo, não há limites geográficos nem custos com sedes físicas. Acredita-se, portanto, que a educação a distância acaba sendo muito procurada, com a promessa de promover maior inserção das pessoas no mercado de trabalho.

Além das vantagens supracitadas, a expansão da modalidade tem sido favorecida pela política adotada no Brasil, uma política neoliberal, com poder reduzido do Estado e pela legislação. Essa política neoliberal, como afirma Negrão (1996, p. 104), está centrada na “ideia da desregulamentação dos mercados, abertura comercial e, especialmente, financeira e na redução do tamanho e papel do Estado". Dessa forma, o Estado promove a mercantilização da educação, tornando-a um comércio, um bem comercializável. Conforme Cardozo et al (2017, p.1) no cenário neoliberal,

a educação é tida como um campo estratégico para o desenvolvimento social, econômico e cultural. Desse modo, um conjunto de grandes organismos multilaterais (Organização das Nações Unidas para a Educação, Ciência e Cultura - UNESCO, Banco Mundial - BM, Organização Mundial do Comércio - OMC) passa a influenciar ideologicamente o campo educacional que, por sua vez, adquire um formato conforme a lógica de mercado, centrado, sobretudo, em processos formativos fundamentados na competividade, na formação de habilidades e competências específicas e na individualização. 
Verifica-se que, neste contexto político neoliberal, a educação busca atender aos interesses mercadológicos, buscando o lucro. Como a educação superior é majoritariamente privada, torna-se um negócio rentável para os grandes grupos educacionais transnacionais que dominam o setor.

Ao se considerar a legislação que tem fomentado a expansão, na busca das origens do processo de normatização da educação a distância, pode-se afirmar que ele se iniciou com a publicação do texto do artigo 80 da Lei de Diretrizes e Bases (LDB) 9.394, de 20 de dezembro de 1996. Desde então, diversas portarias têm sido publicadas, flexibilizando a legislação e permitindo a rápida expansão dos cursos a distância.

A oferta de cursos totalmente a distância foi estabelecida pelo Decreto 9.057, de 25 de maio de 2017, que permitiu a oferta de cursos na modalidade online sem a obrigatoriedade de ter atividades presenciais, o que poderá facilitar ainda mais a expansão da $\mathrm{EaD}$, conforme posto pelo artigo $11 \mathrm{em}$ seu $\S 2^{\circ}$ "É permitido o credenciamento de instituição de ensino superior exclusivamente para oferta de cursos de graduação e de pós-graduação lato sensu na modalidade a distância (BRASIL, 2017)”.

Essa crescente flexibilização é confirmada com a publicação da Portaria 2.117, em 6 de dezembro de 2019, que "dispõe sobre a oferta de carga horária na modalidade de Ensino a Distância - EaD em cursos de graduação presenciais ofertados por Instituições de Educação Superior - IES pertencentes ao Sistema Federal de Ensino”. Essa portaria revoga a anterior, de 28 de dezembro de 2018, e estabelece o limite de 40\% de disciplinas online para os cursos presenciais, desde que obedeçam aos seguintes critérios:

Art. $7^{\circ} \mathrm{Na}$ fase de Parecer Final dos processos de autorização de cursos presenciais, a possibilidade da oferta de carga horária a distância, até o limite de $40 \%$ da carga horária total do curso, além dos critérios estabelecidos pela Portaria Normativa MEC $n^{\circ} 20$, de 21 de dezembro de 2017, está sujeita à obtenção, pelo curso, de conceito igual ou superior a três em todos os indicadores a seguir: I - Metodologia; II - Atividades de tutoria; III - Ambiente Virtual de Aprendizagem - AVA; e IV - Tecnologias de Informação e Comunicação - TIC (BRASIL, 2019)

A portaria anterior, Portaria, de $n^{\circ} 1.428 / 2018$, possibilitava às IES ofertarem até 40\% de disciplinas virtuais, porém, como foi mencionado, essa oferta estava condicionada ao Conceito de Curso acima de 4 (quatro). A portaria de 2019 possibilita a oportunidade de ofertas de cursos online por instituições que tenham conceito de cursos igual ou superior a 3 (três), nos 
indicadores supracitados. Observa-se que a legislação permite a inserção de mais disciplinas a distância nos cursos presenciais, criando, quase uma nova modalidade, chamada muitas vezes de cursos híbrido pois, quase a metade dos atuais cursos são oferecidos online.

Tem sido possível perceber que a expansão da educação a distância oportunizada pela legislação e pelas políticas adotadas pelo governo prioriza a quantidade, espaço aberto amplamente aproveitado pela iniciativa privada, que cresce acentuadamente chegando em 2019 a 2.292.607 matrículas na modalidade a distância em um total de 2.450.264.

Uma observação importante em relação aos dados dos último Censo (BRASIL, 2019) é que este se refere exclusivamente a curso aprovados para serem oferecidos na Modalidade a Distância, não alcançando a oferta das disciplinas virtuais que compõem $40 \%$ dos cursos considerados presenciais. Se tal dado fosse incorporado no atual Censo, os números seriam bem diferentes.

Assim, à medida que $\mathrm{a} \mathrm{ED}$ foi crescendo e se expandindo, novos papéis foram surgindo para atender às demandas que a modalidade apresenta, ameaçando, muitas vezes, o papel dos professores.

$\mathrm{O}$ crescimento da $\mathrm{EaD}$ vem trazendo algumas tensões para a carreira docente, com destaque para a preocupação dos professores dos cursos presenciais ao perderem parte ou até mesmo a carga horária total, uma vez que até $40 \%$ das disciplinas do currículo dos cursos presenciais pode ser ofertada na modalidade a distância.

Outro ponto de tensão é a preparação do professor para atuar nos cursos a distância, devido ao despreparo para a adequada utilização das novas tecnologias. Nascimento (2008, p. 5) pontua que "as novas tecnologias educacionais passam a exigir do profissional docente novas posturas frente ao conhecimento e ao processo cognitivo de aprendizagem de seus alunos". Além de novas posturas, os profissionais têm atuado em novos papéis, como a tutoria e como professores conteudistas. Há ganhos menores no caso das tutorias, sem as garantias que a docência ainda tem e com ganhos pontuais e contratos de prestação de serviço no caso de conteudistas. O receio de perdas dos espaços de atuação provocadas pela expansão dos cursos a distância tem feito os professores procurarem por alternativas. No entanto, esses novos papéis ainda não ofertam condições de trabalho justas aos docentes, funcionando como "atividades temporárias" ou "bicos". 
As exigências profissionais que decorrem dessas mudanças podem se transformar num fator gerador de tensões e insatisfações, pois segundo Davoglio, Spagnolo e Santos (2017, p. 2) "os professores, não raras vezes, sentem-se descontextualizados diante das muitas exigências profissionais e no confronto com a sociedade do conhecimento". As demandas exigidas para esse novo cenário podem causar ansiedade e desconforto.

Ao reforçar a reflexão sobre as práticas pedagógicas, Hardaugh e Camas (2017, p.97) mencionam algumas competências que o docente de cursos online deve possuir, bem como a dificuldade de ministrar aulas com conteúdos que não foram produzidos por esse docente, a ambientação online e a disponibilidade das ferramentas que podem ser fatores determinantes para o sucesso ou fracasso desse trabalho pedagógico.

[...] torna-se também necessário refletirmos como o professor online pode atingir tais competências dentro do modelo hegemônico de educação online, no qual predomina a mecanização da prática docente, à frente do computador, utilizando o conteúdo feito por outro professor especialista e um ambiente virtual, muitas vezes, com poucas ferramentas interativas, quantidade média de alunos de 100 a 200 por turma e sem possibilidade de marcar sua identidade nas estratégias pedagógicas e avaliativas. (HARDAUGH; CAMAS, 2017, p.97)

Logo, as demandas profissionais trazidas pela expansão da modalidade geram tensões sobre perdas de espaços, novas competências e saberes, necessidade de ambientação online e acesso às ferramentas, perda de salários e garantias legais, entre outras que permeiam a carreira docente.

\section{A carreira docente e os novos papéis na educação a distância}

A carreira docente tem sofrido impactos com a expansão da modalidade a distância, trazendo novas demandas, competências e posturas dos docentes. Balbinot et al (2010, p. 2):

O papel do professor vem passando por transformações, pois o ensino mediado por novas tecnologias vem retirando alunos e docentes das salas de aula [...] Essas mudanças requerem novas habilidades do docente e uma nova postura tanto deles quanto dos alunos.

A educação mediada pela tecnologia exige o conhecimento tecnológico, bem como novas habilidades de interação para atuar nesse ambiente virtual, que requer um novo modelo de interação para criar novas conexões com os estudantes, engajando-os e motivando-os.

Considerando-se a legislação que regula a carreira docente, não há informações específicas sobre responsabilidade e atribuições do docente que atua em EaD.

Nunes, Oliveira e Sabino (2019, p. 6) pontuam que 
a análise sobre a legislação brasileira evidencia a desoneração dos agentes regulatórios quanto à preparação docente para o magistério superior na modalidade a distância, indicando um caminho de autoformação do professor, a fim de superar os desafios que se impõem para uma prática pedagógica diversa da modalidade presencial.

Visto que não há normas que tratam especificamente da preparação do docente para sua atuação na modalidade a distância, fica a cargo do próprio docente a responsabilidade por sua formação e capacitação para atuar nessa modalidade.

Quanto ao regime de trabalho, os docentes de instituições privadas possuem contratos estabelecidos por tempo indeterminado, de acordo com a Constituição Federal, artigo $7^{\circ}$ (1988), respeitando a CLT (Consolidação das Leis de trabalho) que expressa no art. 442 "contrato individual de trabalho é o acordo tácito ou expresso, correspondente à relação de emprego" e o regimento interno da própria instituição. Esse contrato de trabalho é firmado a partir das horas semanais trabalhadas.

No entanto, há alguns anos tem havido uma flexibilização da atividade docente nas instituições públicas e privadas, uma vez que diferentes contratos têm sido utilizados e até mesmo permitidos pela legislação. Silva (2018, p. 215) aponta essas tendências no trabalho docente que

estamos presenciando hoje, no Brasil, com o número de professores temporários, eventuais e com algumas tendências de precarização (terceirização, pejotização e uberização) que fazem com que os docentes sejam impedidos de vivenciarem uma vida laboral dotada de algum sentido.

Dias Sobrinho (2010) também havia trazido a discussão sobre a precarização dos contratos de trabalho e a desvalorização do profissional e sua consequente “desprofissionalização", que é a falta do caráter profissional da carreira. Portanto, a carreira docente vem sofrendo desvalorização, perdas salariais, perda de prestígio e respeito.

Essa flexibilização fez surgir a terceirização do trabalho docente, como aponta Silva (2018), e que é ilegal, além de desmotivar os professores. Há aqueles professores que têm outra ocupação e lecionam como um hobby ou complementação de renda, e esses não costumam se importar com contratos de trabalho, além de possuírem menos preocupações com o futuro da carreira. Calderón et al (2008)

acreditam que muitos docentes aceitam essa flexibilização para manterem-se empregados. "A necessidade financeira, aliada à ausência de emprego e falta de opção, é a motivação que apresenta maior incidência e leva os professores aceitar esse regime de trabalho" (CALDERÓN ET AL, 2008, p. 204). 
Os professores, mesmo insatisfeitos com o regime de trabalho, acabam aceitando também por um conflito ético: o amor pela profissão versus a precarização das condições de trabalho. Calderón et al (2008, p. 207) apontam que "há um conflito entre o compromisso ético em relação aos alunos e a realidade trabalhista". Por isso, os docentes se submetem às condições precárias, pela missão de ensinar, e pela responsabilidade com os alunos.

Outro ponto a ser considerado é sobre o plano de carreira nas universidades particulares. Eles costumam ser discutidos e aprovados em reuniões feitas pelo Conselho Universitário (CONSU). Na universidade pesquisada, há um plano de Carreira que se baseia nas leis da CLT e súmula do Tribunal Superior do Trabalho (TST), tratando de equiparação salarial e tempo de serviço na função, por exemplo. Ele estabelece critérios de progressão na carreira docente, com o objetivo de motivar os professores a buscarem a educação continuada, bem como atividades de pesquisa e extensão. Os docentes podem acumular pontuações dependendo da atividade que exercem: orientações participações em bancas, publicações de artigos, participações em Congressos e outros eventos, e como membros do colegiado, conselhos, coordenações, entre outros.

Apesar do plano de carreira existente, a promoção pode ser lenta e burocrática. Outras instituições não possuem planos de carreira e, nos últimos anos, têm causado tensões entre os professores devido à instabilidade que promovem ao efetuarem demissões em massa. A carreira docente nestas universidades é pautada pela tensão ao final de cada semestre, com a incerteza gerada pelas demissões que costumam ocorrer neste período.

Além disso, como o currículo é dinâmico e a legislação permite as mudanças, há a constante tensão sobre a redução de carga horária que pode ocorrer devido à extinção de disciplinas e ou a migração delas para o ambiente virtual. Neste caso, não haveria a necessidade de professores, talvez de tutores, e o docente que ministrava as disciplinas pode acabar ficando com uma carga horária mínima, ou até sem aulas para ministrar.

Mesmo neste cenário marcado pela flexibilização dos contratos de trabalho e da instabilidade e insegurança gerada pela carreira docente nas instituições privadas, a configuração da modalidade a distância possibilitou novos espaços de atuação, ou novos papéis para os docentes, pois a reinvenção da carreira docente tem sido exigida. A atuação dos docentes tem sido possível como tutores, professores conteudistas, designer instrucionais, analistas de conteúdo, produtores de vídeo, entre outros. Essas novas possibilidades de atuação têm tomado 
o mercado e exigido requisitos específicos. No entanto, não há uma legislação própria para essas novas profissões e a falta de leis e de transparência sobre a atuação desses profissionais faz com que eles se exponham a condições adversas de trabalho.

Esses postos de trabalho costumam ser ofertados por meio de um contrato de trabalho, e o docente é obrigado a ceder os direitos autorais referentes à produção escrita e de vídeos. Como as relações estabelecidas são via contratos de trabalho, não criam vínculos empregatícios, e não geram direitos trabalhistas. Entretanto, apesar de haver novas possibilidades de atuação, as relações de trabalho estabelecidas são diferentes e não regulamentadas. Esses papéis têm mostrado uma crescente demanda e relevância, porém os docentes têm sofrido com a falta de transparência, contratos que não os beneficiam, altas exigências e remunerações não condizentes e prazos de pagamento que se estendem por um longo período de tempo. Portanto, mesmo com o surgimento desses novos papéis, há tensões que permeiam o futuro da carreira docente.

\section{Perspectivas de futuro da carreira docente}

A sociedade tem se transformado de forma bastante dinâmica, e os professores têm sentido as pressões que as mudanças políticas, econômicas e sociais provocam na prática docente.

Hagemeyer (2004, p. 70) pontua que "a profissão docente, nas últimas décadas, se depara com um processo de valorização/desvalorização, crítica e perda de identidade". Esse processo de desvalorização vem sendo intensificado devido às transformações sociais pelas quais o mundo vem passando. Sella (2006, p. 46) diz que essas transformações "são comprovadas através da complexidade dos problemas que afetaram o sistema educacional. Sem soluções plausíveis e imediatas há um enfraquecimento do nível de ensino e um crescente desgaste do professor". Portanto, tem havido um desgaste da imagem, função e papel do professor.

Gatti, Barreto e André (2011, p. 25) afirmam que há uma distância entre aquilo que o professor idealiza e o que de fato realiza:

Cada vez mais, os professores trabalham em uma situação em que a distância entre a idealização da profissão e a realidade de trabalho tende a aumentar, em razão da complexidade e da multiplicidade de tarefas que são chamados a cumprir $[\ldots]$

De acordo com os autores, a carreira docente tem proporcionado angústias, devido à precarização das condições do trabalho, que não são benéficas à imagem e autoestima docentes. 
O cenário no qual os professores atuam e o foco e as suas formas de atuação têm demandado complexidade crescente. A essa "complexificação" da condição docente aliam-se a precarização de suas condições de trabalho no contexto comparativo do exercício de outras profissões e as dificuldades de manter condições favoráveis para autoestima e, em sua representação, criar estima social (GATTI; BARRETO; ANDRÉ, 2011, p. 25).

A desvalorização da carreira gera desmotivação e insatisfação, além de corroborar com o surgimento de doenças físicas e mentais. Sella (2006) pontua que essa desvalorização do trabalho docente provoca o surgimento

de sintomas mais amenos a outros bem complicados, em diversas situações, o "mal-estar" provoca o afastamento do docente [...] Este "mal-estar" vai concretizar-se em absenteísmo, em pedidos constantes de transferências, em estresse, em doenças mais ou menos fingidas para abandonar momentaneamente a docência, e por fim, em doenças reais, em neuroses ou depressões mais ou menos graves. (SELLA, 2006, p. 110)

A desvalorização da carreira docente tem provocado mal-estar, estresse, baixa autoestima, depressão, entre outros problemas físicos e mentais.

Soma-se a essa precarização, uma imagem de uma carreira pouco profissional. Arroyo (2000, p. 193) corrobora com essa visão quando traz provoca a reflexão de que a imagem do docente

tem pouco de profissional e de específico, qualquer um pode fazer desde que saiba esses saberes e seja treinado. Essa imagem tem pouco de pública, pois reproduz e serve à lógica do privado, do mercado.

Além da desvalorização social da docência, Sella (2006, p. 46) menciona que "as últimas décadas foram marcadas pelas progressivas perdas salariais. Isso pode ser observado mais facilmente se analisadas sob o ponto de vista do poder aquisitivo do professor". A carreira dos professores tem sido marcada por lutas por salários mais compatíveis com a função, que exige um trabalho dentro e fora do ambiente escolar.

Assim, as perdas salariais, devido à precarização do trabalho, bem como o desprestígio da carreira docente contribuem para a desmotivação e a baixa autoestima dos professores. Sella (2006, p. 47) pontua que a perda do prestígio social está diretamente ligada aos baixos salários. "Como o status social é estabelecido em termos exclusivamente econômicos, a função docente passa a ser considerada como ocupação de quem não consegue algo melhor."

O trabalho docente é visto como um trabalho que qualquer pessoa poderia fazer, pois, como afirma Sella (2006 p. 47), “a falta de valorização e de reconhecimento do professor não 
consegue ultrapassar a leitura do profissional como sendo uma categoria diferenciada das demais". A própria sociedade vem internalizando essa ideia, especialmente quando perguntam a um docente "Você também trabalha ou só dá aula?".

Além de lidar com a precarização do trabalho, desvalorização da carreira, estresse e surgimentos de doenças ocupacionais, há as exigências de novas práticas e novos saberes no exercício de suas funções, para que os professores possam manter sua empregabilidade. Esses novos saberes dizem respeito às plataformas virtuais de aprendizagem, ferramentas tecnológicas, novas formas de interação, entre outros. A falta de domínio dessas estratégias gera tensões, estresse e angústias, especialmente em relação ao futuro.

Gatti, Barreto e André (2011) mencionam alguns fatores para que os docentes aumentem a percepção de que sua carreira pode ser mais promissora no futuro: imprescindível valorização profissional; condições de trabalho articuladas ao plano de cargos e carreiras; formação inicial e continuada de qualidade e avaliação como processo que retroalimente a tarefa de ensinar.

O trabalho docente não se limita apenas a ensinar conteúdos, pois é pautado pelo auxílio aos estudantes na preparação para a vida, para que trilhem um caminho de realizações. O docente, além de proporcionar uma perspectiva de futuro para seu alunado, possui também sonhos e anseios em relação à sua própria carreira. Segundo Sacristán $(2015$, p.11):

Somente podemos contemplar a educação em uma perspectiva de futuro. Embora seja realizada no presente, sempre dará seus frutos não hoje, mas no futuro, em um momento que estará mais ou menos próximo do presente. Essa condição tem que nos importar, precisamente por isso, porque educar é fazer algo pelo "dia de amanhã", que é dos outros que nos seguirão. A educação é uma atividade que realizamos porque acreditamos na promessa de que o futuro se realizará, o qual esperamos que seja melhor. Uma promessa que nos faz confiar em algo que queremos e não é, mas chegará a sê-lo.

Desse modo, se a expansão da modalidade EAD tem trazido tensões, angústias e desmotivação, em que condições este professor vai trabalhar no presente? Como administrar as tensões, que incluem instabilidade e precarização da carreira, ameaças de perdas de espaço, redução de salários a carga horária, além do desprestígio social? Que perspectiva, motivação e planejamento esse docente terá para o futuro de sua carreira?

\section{Dados coletados na Instituição Universitária Privada: o que dizem os professores}

Ao traçar o perfil dos respondentes, e verificou-se que 50,7\% dos professores possuem mais de 50 anos, e este foi um dado que chamou a atenção, pois está acima da média nacional 
segundo o Censo do INEP (2018), que é de 38 anos. Não houve professores de 20 a 30 anos entre os respondentes. Além disso, 56,9\% são do gênero masculino, corroborando com o Censo INEP, que diz que os docentes mais frequentes na educação superior, tanto pública, quanto privada, são homens. A área de atuação predominante é a de Exatas: 43,2\%.

Esse dado é surpreendente, pois esperava-se encontrar mais respostas de professores da área de Educação, pois, estes representam a maior parte dos docentes que possuem apenas a carreira docente como fonte de renda. E talvez por este motivo, os professores da área de Educação poderiam mostrar-se mais tensos com a expansão da EaD. Os professores da área de Exatas, por terem outros trabalhos e ministrarem aulas como uma alternativa prazerosa ou mesmo na busca de complementar os rendimentos, confirmando a pesquisa de Calderón et al (2008) , trazem, portanto, uma visão mais positiva sobre o futuro da carreira docente, por não se preocuparem com a perda de espaços de atuação.

Observando-se a titulação dos respondentes, 75,4\% dos docentes possuem mestrado e doutorado e 7,7\% possuem pós-doc. A titulação é uma maneira de manter a empregabilidade. Há mais professores com mestrado, 36,9\%, e isso corrobora com os dados obtidos pelo censo do INEP, que traz a informação de que a maioria dos docentes na educação superior privada possui mestrado como titulação máxima.

Sobre o tempo de experiência, 43,1\% dos docentes têm entre 10 e 20 anos de carreira docente, e os 65 respondentes ministram aula na modalidade presencial. Apenas 13 deles, ou 20\%, ministram aulas nas duas modalidades: presencial e a distância. 50,8\% tiveram experiência anteriores em trabalhar nos cursos a distância.

Esperava-se que os docentes que nunca ministraram aula nos cursos EaD pudessem ter mais resistência, porém, 30,7\% desses docentes acreditam num futuro de carreira promissor. Essa perspectiva mais positiva pode ser devido aos novos papéis que têm surgido, já que 3 professores mencionam essas possibilidades de trabalho. Por exemplo, o professor 6 afirma que “na EaD há diferentes papéis. A noção tradicional de professor é ampliada. Podemos ter professor responsável, professor conteudista, tutor, possibilitando graus de atuação em diferentes níveis."

Entre os professores que têm experiência na modalidade a distância, 63,6\% têm uma perspectiva otimista sobre o futuro da carreira docente, tanto presencial quanto a distância. Os professores mais pessimistas sobre a carreira docente presencial pontuam a redução de aulas e 
altos custos para manterem os professores em sala de aula como razões para justificar essa visão mais negativa.

Os docentes que possuem outra carreira, 52,3\% dos respondentes, mostram uma visão mais otimista do futuro da carreira, tanto presencial quanto a distância, talvez por não possuírem a docência como sua principal fonte de renda. Entretanto, se considerarmos os 32 professores que não possuem outra ocupação, 16 deles tem o tom mais pessimista em relação ao futuro da carreira docente presencial e outros 9 acreditam que a carreira a distância não é, definitivamente, promissora.

Alguns dos professores que acreditam no futuro da carreira presencial comentam as vantagens dos cursos presenciais em comparação com a modalidade a distância, como o professor 46, que afirma: "Sempre teremos alunos que preferem os cursos presenciais devido ao acesso a literatura e explicação dos professores capacitados". O professor 33 pontua que “com a proliferação do EaD, os cursos presenciais, bem como os seus docentes, se tornarão raros e preciosos. Ainda que haja a tecnologia a nosso favor, o aprendizado e a troca em sala de aula são insubstituíveis".

O professor 21 traz uma vantagem da modalidade presencial, pontuando que "os alunos têm a possibilidade de fazer networking, o que não acontece no EaD, perdendo oportunidades de conseguir um emprego por indicação, por exemplo". Infere-se que, para alguns professores, os cursos presenciais continuarão ofertando possibilidades de atuação.

Três docentes mencionaram a precarização da educação e as tensões relacionadas às perdas de direitos: os professores 9 e 15 apontaram "a precarização das condições de trabalho" e o professor 58 pontuou que haverá um "baixo retorno financeiro, e pagamento somente para gravação, sem direitos autorais". Esse professor se refere a uma das possíveis atuações dos docentes, como conteudista, que escreve os materiais pedagógicos e grava vídeo-aulas assinando contratos de cessão total de direitos. Essa é uma preocupação com os novos papéis, por exemplo, que podem não oferecer condições apropriadas de trabalho.

Quanto à visão mais pessimista, o professor 37 levanta um fato relevante: "Será cada vez menor a atuação docente presencial, e os cursos cada vez menos procurados, devido ao custo alto e necessidade de presença em sala de aula", inquietação confirmada pelos dados levantados pelo Censo do Inep de 2019 (BRASIL, 2019)e da ABED (2018, p. 121), que apontam 
uma queda nos cursos presenciais. Essas informações podem ser um dos fatores geradores de tensões para os docentes.

O professor 31 acredita que o professor da modalidade presencial será desvalorizado. Ele diz que "haverá uma subvalorização do professor que atua no ensino presencial em detrimento daquele que atua no ensino a distância". Há docentes bem pessimistas quanto ao futuro da EaD. O professor 36 afirma que "a modalidade EaD fará com que não se tenha mais interesse pela área acadêmica". E o professor 30, ao responder sobre a perspectiva da carreira na educação presencial, ressaltou a transformação da educação superior num comércio, ao dizer "Tenebroso, universidades visarão apenas lucro e o curso EaD será o meio para lucros maiores", posição que indica que a precarização e intensa mercantilização da educação vivenciada pela área educacional também preocupa os docentes.

Outros docentes apontam, ainda, a precarização da educação e a tensão referente à perdas de direitos trabalhistas como mencionam os professores 9 e 15 "a precarização das condições de trabalho".

Referente às tensões que a expansão da EaD tem causado aos professores, verifica-se que a redução de espaços de atuação é a mais temida por 46 professores, ou 70,8\%. Ao observarmos o gráfico abaixo, mesmo com uma perspectiva de carreira mais otimista, infere-se que os professores acreditam que a carreira docente esteja passando por um momento crítico, que gera as tensões mencionadas. Apenas dois professores, entre os 65 respondentes, não reconhecem nenhuma tensão provocada pela expansão da EaD.

Gráfico 1 - Tensões reconhecidas pelos respondentes 


\section{1 - Alguns docentes entendem que há tensões causadas pela expansão da EAD. Marque as que você concorda e adicione outras, se desejar.}

65 responses

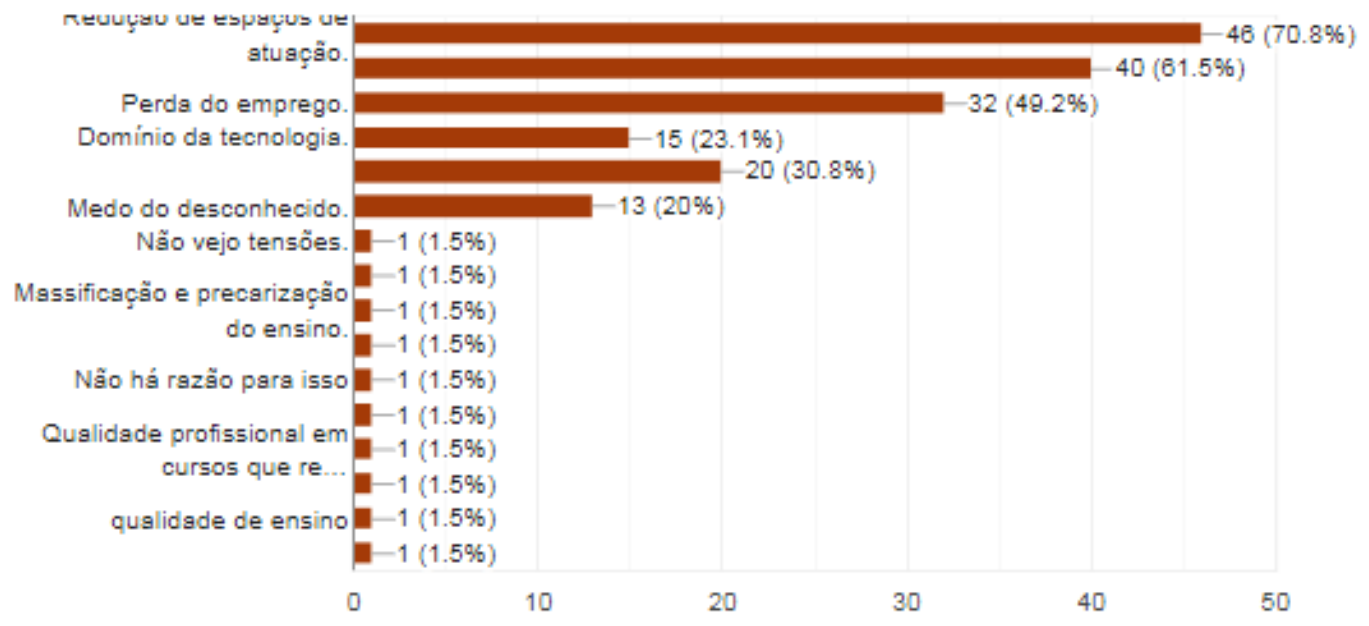

Fonte: dados da pesquisa (2019)

Outras tensões confirmadas pelos docentes são perda do emprego, perdas salariais e condições de trabalho precárias, falta de apoio institucional, abordagem muito tecnicista, redução do número de horas-aula, menos postos de trabalho, excesso de alunos. O domínio de novos saberes, especialmente referentes à tecnologia, também é um fator de preocupação para 15 professores. Porém, o professor 59 acredita que "apenas os mais capacitados e experientes terão espaço", reforçando a ideia de que a formação continuada seria uma alternativa para manter a empregabilidade.

\section{Considerações finais}

O objetivo geral dessa pesquisa foi o de analisar as perspectivas do docente da educação superior presencial privada sobre a própria carreira num cenário de expansão da educação a distância na graduação. Para tanto foi necessário compreender as políticas para a educação superior a distância no Brasil e conhecer o que pensam os professores dos cursos presenciais de educação sobre a docência na $\mathrm{EaD}$, para identificar as tensões que estão sendo provocadas pela 
expansão da modalidade a distância e pelo aumento substancial de disciplinas virtuais nos cursos presenciais. Além disso, o estudo considerou os novos papéis que têm surgido na área, as tensões geradas por esse crescimento dos cursos a distância, e, também as ações que os docentes acreditam ser possíveis para manterem seus espaços de atuação

O percurso metodológico escolhido iniciou com a elaboração de questionários, coleta dos dados e posteriormente a elaboração de conjecturas, categorização e análise das respostas obtidas nas perguntas objetivas e abertas.

Os resultados a serem destacados referem-se ao fato de professores mais experientes possuírem uma visão mais positiva do futuro da carreira; os docentes que possuem outra ocupação também têm perspectivas mais otimistas, enquanto os respondentes que possuem apenas a docência como fonte de renda mostraram uma tendência mais pessimista ao futuro da carreira presencial, mas, mais otimista em relação à modalidade a distância. Outro ponto relevante é o de que os professores com mais experiência em cursos a distância possuem uma visão e perspectiva mais positivas em relação ao futuro. Muitos docentes entrevistados acreditam nas novas possibilidades de atuação que o mercado tem proporcionado.

Acreditava-se que o fato dos professores não ter experiência em $\mathrm{EaD}$ os tornaria mais resistentes e com visões e perspectivas mais pessimistas dessa modalidade. Na verdade, o que se observou foi o contrário, os professores sem experiência em EaD estão mais inclinados a investirem na formação continuada e têm uma perspectiva mais otimista em relação ao futuro da carreira.

Interessante observar que os docentes pertencentes à maior faixa etária, de 60-70 anos, que, supostamente, teriam mais resistência e estariam tensos em relação à aquisição de novos saberes e capacitação adequada para $\mathrm{EaD}$, foi desmentida pela pesquisa, pois, esses professores mostraram-se otimistas e abertos ao novo, ainda querendo estudar e aprender para auxiliar seus alunos.

Considerando-se a pergunta da pesquisa, sobre as perspectivas da carreira docente frente à expansão da EaD, observou-se que a visão e perspectiva de carreira docente é, em geral, mais otimista, mesmo considerando as tensões geradas pela expansão da educação a distância, que pode ameaçar alguns docentes com perdas de espaço de atuação, condições de trabalho não apropriadas, redução de jornada de trabalho e de salários, excesso de alunos, abordagem demasiadamente tecnicista, e exigência de novos saberes, especialmente os relacionados à 
tecnologia. Mesmo os professores que possuem uma visão mais positiva confirmaram a existência dessas ameaças.

Os professores, de um modo geral, mostram-se otimistas com o futuro da carreira docente, tanto na modalidade $\mathrm{EaD}$, quanto na presencial. Há uma crença presente entre os docentes que, independente da modalidade, sempre haverá espaço para os professores. E, muitos docentes já admitem os novos papéis da modalidade a distância, entre estes, o de conteudista, tutores e outros, como novas alternativas para continuarem na carreira.

No entanto, mesmo diante de da instabilidade, incerteza e desprestígio que a carreira docente pode significar neste momento, mesmo considerando todas as ameaças e tensões reconhecidas pelos respondentes e apontadas pelo estudo, os docentes acreditam que precisam se adaptar às mudanças e aos novos papéis que têm surgido, buscando a formação continuada por meio de cursos, titulações, para minimizarem as perdas, manterem seus empregos e garantir seus espaços de atuação.

Assim, a pesquisa evidencia que o docente da educação superior privada em atuação trabalha administrando essas tensões, segue apostando na formação continuada como a chance de sobrevivência no mercado, além de estar aberto para novas alternativas profissionais, migrando para papéis que nem sempre são, reconhecidamente, uma função docente. Pelos dados da investigação foi possível perceber que estes professores fazem da ameaça iminente da perda de empregos como motivação para buscarem alternativas de trabalho que o novo cenário tem imposto. O desprestígio que admitem, tanto no que se refere aos rendimentos como na desvalorização social, os incomoda, mas, talvez esses professores sigam em frente devido à falta de outras oportunidades, ao idealismo ou simplesmente porque é o seu ganha-pão.

Entretanto, faz-se necessário reafirmar que o cenário enfrentado pelos professores da rede privada de educação superior é ameaçador, uma vez que esses profissionais não têm nenhuma garantia de permanência em seus empregos, mesmo com a aceitação da nova modalidade e seu impacto na redução de vagas para docentes.

Os docentes reconhecem ainda, que há uma acelerada substituição do ensino presencial pela educação a distância impondo a todos que ou se adequem ao novo modelo e encontrem alternativas de empregabilidade ou serão deixados pelo caminho e, surpreendentemente, conseguem acreditar que encontrarão espaço e manterão seus empregos. 
A pesquisa desvela áreas que precisam ser melhor compreendidas, no que se refere às discussões acerca da modalidade a distância, principalmente nas instituições universitárias privadas, sobretudo pela acelerada expansão da modalidade que avança sobre os cursos presenciais, colocando em pauta questões relacionadas com a qualidade de ensino, futuro dos professores e empregabilidade dos novos graduados.

\section{Referências}

Abed. (2017). CENSO EAD.BR: Relatório Analítico da Aprendizagem a Distância no Brasil 2017. Curitiba: InterSaberes. Disponible http://www.abed.org.br/site/pt/midiateca/censo_ead/1554/2018/10/censoeadbr_2017/2018

Arroyo, M. G (2000). Oficio de Mestre: imagens e autoimagens. Petrópolis: Vozes.

Balbinot, A. B.; Bulegon, A. M.; Oliveira, E. H. T.; Behar, P. A.; Portella, V. C. C. (2010). A prática docente em educação a distância: o uso do modelo metodológico dos três momentos pedagógicos. UFRGS, 8 (3). Disponible en: https://seer.ufrgs.br/renote/article/view/18108

Brasil. (1998). Constituição da República Federativa do Brasil de 1988. Brasília, DF: Congresso Nacional. Disponible en: http://www.planalto.gov.br/ccivil_03/leis/19601.htm

Brasil. (1943). Consolidação das Leis de Trabalho. Decreto-Lei no 5.452, de 1 de maio de 1943.

Brasil. (1996). Lei $n^{\circ}$ 9.394, de 20 de dezembro de 1996. Lei de diretrizes e bases da educação nacional. Disponible en: http://www.planalto.gov.br/ccivil 03/leis/19394.htm

Brasil. (2017). Decreto ${ }^{\circ}$ 9.057, de 25 de maio de 2017. Brasília, DF, 2017. Regulamenta o art. 80 da Lei $\mathrm{n}^{\circ}$ 9.394, de 20 de dezembro de 1996, que estabelece as diretrizes e bases da educação nacional. Disponible en: http://www.planalto.gov.br/ccivil 03/_Ato20152018/2017/Decreto/D9057.htm

Brasil. (2018) Portaria $n$. 1.428, de 28 de dezembro de 2018. Disponible en: https://www.in.gov.br/materia/asset publisher/Kujrw0TZC2Mb/content/id/57496468/do1-2018-12-31-portaria-n-1-428de-28-de-dezembro-de-2018-57496251

Brasil. (2019). Portaria $n^{\circ} 2.117$, de 6 de dezembro de 2019. Dispõe sobre a oferta de carga horária na modalidade de Ensino a Distância - EaD em cursos de graduação presenciais ofertados por Instituições de Educação Superior - IES pertencentes ao Sistema Federal de Ensino. Disponible en: http://www.in.gov.br/en/web/dou//portaria-n-2.117-de-6-dedezembro-de-2019-232670913

Brasil. MEC/INEP. (2019). Censo da Educação Superior. Disponible en: http://portal.inep.gov.br/web/guest/microdados

Brasil. MEC/INEP. (2018). Censo da Educação Superior. Disponible en http://portal.inep.gov.br/web/guest/microdados 
Brasil. TRT-23 - RO: 00007194720165230004, Relator: NICANOR FAVERO FILHO, $1^{\mathrm{a}}$ Turma-PJe, Data de Publicação: 17/05/2017. Disponible em: https://www.tst.jus.br/sumulas

Calderon, A. I.; Martins, F.; Lourenço, H. S.; Moraes, R. (2008). Terceirização na educação superior: o trabalho docente por meio de cooperativas de mão-de-obra. Eccos Revista Científica. São Paulo, 10 (1), pp.189-212. Disponible en: https://periodicos.uninove.br/eccos/article/view/1057/1011

Cardozo, E. N. R., Miranda, A. L. F., Santos, M. S.; Pessoa, L. N. F. (2017). Educação e Neoliberalismo em contexto brasileiro: elementos introdutórios à discussão. Curitiba: Educere. Disponible en: https://educere.bruc.com.br/arquivo/pdf2017/25724 12514.pdf

Davoglio, T.C.; Spagnolo, C.; Santos, B. S. (2017). Motivação para a permanência na profissão: a percepção dos docentes universitários. Psicologia Escolar e Educacional. São Paulo, 21 (2), pp. 175-182. Disponible en: http:/www.scielo.br/pdf/pee/v21n2/2175-3539pee-21-02-00175.pdf

Dias Sobrinho, J. (2010). Democratização, qualidade e crise da educação superior: faces da exclusão e limites da inclusão. Revista Educação e Sociedade. [online]. 31 (113), pp.12231245. Disponible en: http://www.scielo.br/pdf/es/v31n113/10.pdf

Gatti, B. A.; Barreto, E. S. S.; André, M. E. D. A. (2011). Políticas docentes no Brasil: um estado da arte. Brasília: UNESCO.

Hagemeyer, R. C. C. (2004). Dilemas e desafios da função docente na sociedade atual: os sentidos da mudança. Revista Educar, Curitiba, n. 24, pp. 67-85. Disponible en: http://www.scielo.br/pdf/er/n24/n24a04.pdf

Hardaugh, C. C. e Camas, N. P. V. (2017). (De)formando o educador: uma discussão teórica acerca do tutor na EaD. Laplage em Revista, 3 (2), pp.94-108. Disponible en: https://dialnet.unirioja.es/servlet/articulo? codigo $=6193626$

Nascimento, F. P.; Carnielli, B. L. (2008). Educação a distância no ensino superior: expansão com qualidade? Campinas: Educação Temática Digital, 9 (1), pp. 84-98. Disponible en: https://periodicos.sbu.unicamp.br/ojs/index.php/etd/article/view/740

Negrão, J. J. O. (1996). O governo FHC e o neoliberalismo. Lutas Sociais. São Paulo: Neils/Xamã, n. 1, pp. 103-111.

Nunes A. K. F.; Oliveira A. V. B.; Sabino, R. F. (2019). Docência na educação a distância: abordagem sobre o perfil professional. Revista Internacional de Educação Superior. Campinas, $\quad$ SP, $\quad$ v. $5 . \quad$ Disponible en: https://www.researchgate.net/publication/328678319 Docencia_na educacao_a distancia abordagem sobre o perfil profissional

Sacristán, J. G. (2015). Por que nos importamos com a educação no futuro? In: Imbernón, F.; Jarauta, B. (orgs.). Pensando no futuro da educação: uma nova escola para o século XXI. [s.1.]: Porto Alegre: Penso.

Sella, C. A. (2006). Retratos de um profissional em crise: os docentes em tempos de mudança. 2006. 123f. Dissertação de Mestrado em Educação. Universidade do Oeste de Santa Catarina, Joaçaba. 
"Politicas, Programas y Prácticas de Formación de Profesores"

Silva, E. M. (2018). Os professores de ensino superior e as pressões normativas para atuação na educação a distância. Tese de doutorado. Pontifícia Universidade de Belo Horizonte. 